\title{
Supported UV Polymerized Ionic Liquid Membranes with Block Copolymer
}

Gigi George $^{2}$, Nidhika Bhoria ${ }^{2}$ and Vikas Mittal ${ }^{1 *}$

${ }^{1}$ Department of Chemical Engineering, The Petroleum Institute, Abu Dhabi, UAE

${ }^{2}$ Department of Chemical and Environmental Engineering, University of Toledo, Toledo, USA

*Corresponding author: Vikas Mittal, Department of Chemical Engineering, The Petroleum Institute, Abu Dhabi, UAE, Tel: +97126075491; E-mail: vmittal@pi.ac.ae

Received date: May 01, 2016; Accepted date: November 14, 2016; Published date: November 20, 2016

Copyright: ( 2016 George G, et al. This is an open-access article distributed under the terms of the Creative Commons Attribution License, which permits unrestricted use, distribution, and reproduction in any medium, provided the original author and source are credited.

\begin{abstract}
In this study, the use of UV polymerizable Room Temperature lonic Liquid (RTIL) with a block copolymer has been investigated for the generation of composite membranes for potential separation of acidic gases from natural gas streams. Use of RTILs is known to provide significant mass transportation enhancement but with significant shortcomings such as leaching. In order to avoid this limitation, UV polymerized RTIL membranes with poly(ether-bamide) have been generated with superior mechanical and thermal properties. Two different synthetic approaches were utilized in the current study to obtain the supported membranes with different structural aspects, thus, confirming the possibility to control the structure and resulting properties of the membranes.
\end{abstract}

Keywords: Copolymer; RTIL; Membranes; UV polymerization; Mechanical properties; Thermal stability; Peak melting point

\section{Introduction}

Room temperature ionic liqulids (RTILs) are useful materials for generating supported ionic liquid membranes (SILM) due to their selectivity for acid gases e.g. $\mathrm{CO}_{2}$ and $\mathrm{H}_{2} \mathrm{~S}$, low vapor pressure as well as 'green' nature. RTILs are reported to have higher mass transport coefficients than traditional membranes generated from a variety of polymeric matrices, thus, leading to higher permeabilities and diffusivities [1-3]. A number of studies have reported on SILM for separation of $\mathrm{CO}_{2} / \mathrm{CH}_{4}, \mathrm{CO}_{2} / \mathrm{N}_{2}$ [4], olefin/ paraffin [5,6], etc. However, this prominent attribute suffers from IL clusters' fragile nature within the polymeric membranes, thus, leading to their leaching from surface and reduction in performance $[7,8]$. An alternative is to polymerize the RTILs either as homopolymers or copolymers [9]. Poly (ionic liquids) (PRTIL) have been demonstrated to possess higher $\mathrm{CO}_{2}$ adsorption capacities than the respective monomers [8]. Separation ability was not reduced at the partial $\mathrm{CO}_{2}$ operating pressures of 207 $\mathrm{kPa}$ [4]. Another work investigated the effect of polymerized and 'free' RTIL percentage on a composite gel membrane for $\mathrm{CO}_{2}$ separation [10]. Polymerization percentage had different effects on $\mathrm{CO}_{2}$ permeability depending on the RTIL content of the composite membrane. Highest permeability was obtained with RTIL content of $75 \%$ (free). Other works have investigated polymerized RTIL/liquid RTIL composite membranes for $\mathrm{CO}_{2}$ separation [11]. A maximum selectivity of 24.9 was reported for $\mathrm{CO}_{2}$ from a mixture with $\mathrm{CH} 4$. Such membranes had been extremely selective for $\mathrm{CO}_{2}$ in $\mathrm{CO}_{2} / \mathrm{CH}_{4}$ mixtures [12] in previous works as well. However, other studies have also shown that polymerization of RTILs led to lower diffusivities and permeabilities [2,13]. UV irradiation of an UV active initiator is an effective method for polymerizing monomers containing a specific polymerizable group. UV energy is adsorbed by the initiator, thus generating free radicals or ions that initiate the polymerization process. RTILs have also been reported to polymerize using UV irradiation methods [14]. PEBAX is a poly(ether-b-amide) block copolymer composed of an amorphous rubbery polyether segment and a semi- crystalline hard polyamide segment. The copolymer has been extensively studied for $\mathrm{CO}_{2}$ gas separations $[15,16]$. It contains $40 \%$ polyamide (PA) and $60 \%$ polyethylene oxide (PEO) and is hydrophilic in nature. PA segments provide crystalline regions as well as mechanical stability while the PEO component governs the chain mobility and the gas transport properties. To combine the advantages of both copolymer matrix and the RTILs, composite membranes have also been reported. Recent experimental works have reported $\mathrm{CO}_{2}$ and $\mathrm{H}_{2}$ permeabilities of 330-350 and 7-8 Barrers, for PEBAX-1657/ [C4mim][TfO] and [C2mim][BF4], respectively $[17,18]$. However, no study describing the incorporation of polymerized RTIL with PEBAX has been reported.

This work aims to develop the synthesis processes of a series of supported UV polymerized ionic liquid membranes with block copolymer for potential application as gas separation membranes. Two different synthetic routes for incorporation of block copolymer with PRTIL were explored and the membranes were characterized for their structural, thermal and mechanical properties.

\section{Experimental}

\section{Materials}

Room temperature ionic liquid monomer 2-(methyl acryloyloxy) ethyl-trimethyl ammonium tetrafluoro borate] [MATMA][BF4] was provided by BASF Germany. Figure 1 demonstrates the chemical structure of [MATMA][BF4]. Photo initiator (PI) 2-hydroxy-2-methyl propiophenone, N,N' dimethylformamide (DMF) and dimethyl sulfoxide (DMSO) were purchased from Sigma Aldrich. Block copolymer PEBAX $1657^{\circ}$ was supplied by Arkema in pellet form and was used as received without any further treatment $[19,20]$.

\section{Membrane synthesis}

Two different synthetic approaches were utilized to achieve membranes, namely Scheme 1 and 2. The amount of PI was kept constant as 5\% while the UV exposure periods of 15, 30 and $60 \mathrm{~min}$ were used to optimize the quality of polymerization. UV cured RTIL 
solution was solvent casted and air dried followed by vacuum drying for complete solvent removal.

a)
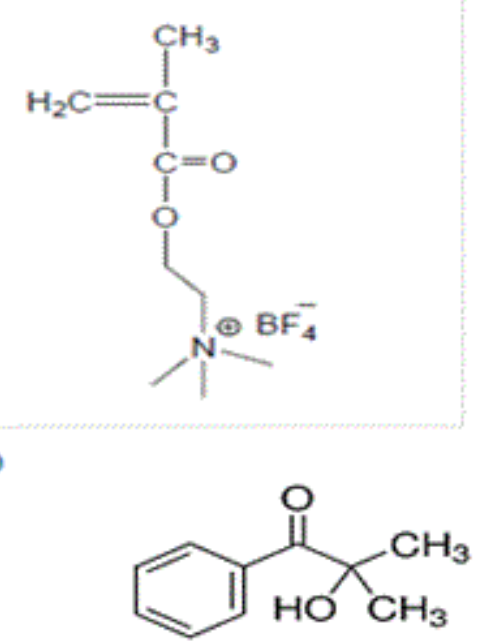

b)

Figure 1: Chemical structure of (a) 2-(methyl acryloyloxy) ethyltrimethyl ammonium tetrafluoro borate] [MATMA][BF4] and (b) 2-Hydroxy-2-methylpropiophenone.

Scheme 1: RTIL and photo-initiator (PI) were mixed in DMF and placed under UV radiation for photo-polymerization. Short wave UV lamp was used for polymerizing the RTIL. The short wave UV radiations were imposed using a 45130 model Leybold Didactic $\mathrm{GmbH}$, spectrum lamp made in Germany. Subsequently, the copolymer was dissolved at $10 \% \mathrm{w} / \mathrm{w}$ in DMSO by heating to $90^{\circ} \mathrm{C}$ and stirred for $24 \mathrm{~h}$.

The PRTIL was dissolved in DMSO and added to the copolymer solution. The solution was stirred for $15 \mathrm{~min}$ to ensure homogeneity of the mixture. PRTIL mass ratio in the new mixture was fixed to $50 \%$.

The membranes were casted by controlled solvent evaporation. The membranes were air-dried at $60^{\circ} \mathrm{C}$ for $24 \mathrm{~h}$ and further vacuum dried at $80^{\circ} \mathrm{C}$ for $48 \mathrm{~h}$. The membranes were casted immediately after the preparation of solution so as to avoid formation of gel upon cooling.

Scheme 2: The second synthetic route included the preparation of copolymer - RTIL mixture and subsequent UV photo-polymerization. The copolymer was dissolved at a concentration of $10 \mathrm{w} / \mathrm{w} \%$ in DMSO, heated at $90^{\circ} \mathrm{C}$ and stirred for $24 \mathrm{~h}$. RTIL and $5 \%$ of photo-initiator were dissolved in DMSO and added to copolymer solution. The solution was stirred for $15 \mathrm{~min}$ to ensure homogeneity.

The new solution (block copolymer+RTIL+PI) was placed under UV radiation for $30 \mathrm{~min}$ followed by solvent casting. RTIL mass ratio was fixed at $50 \% \mathrm{w} / \mathrm{w}$. The membranes were air-dried at $60^{\circ} \mathrm{C}$ for $24 \mathrm{~h}$ and further vacuum dried at $80^{\circ} \mathrm{C}$ for $48 \mathrm{~h}$. For comparison studies, the RTIL monomer was also polymerized under UV light and denoted as $\mathrm{P}([\mathrm{MATMA}][\mathrm{BF} 4])$. Similarly, membranes of pure copolymer were also generated.

\section{Characterization}

TA Discovery series differential scanning calorimetry was used to determine calorimetric properties of the samples. Second heating runs from $-60^{\circ} \mathrm{C}$ to $250^{\circ} \mathrm{C}$ at a heating rate of $10^{\circ} \mathrm{C} / \mathrm{min}$ were analyzed. TA Discovery series thermal gravimetric analysis was used to determine the thermal properties under nitrogen atmosphere. Sample sizes in the range $7-10 \mathrm{mg}$ were subjected to heating from $30^{\circ} \mathrm{C}$ to $700^{\circ} \mathrm{C}$ at a rate of $10^{\circ} \mathrm{C} / \mathrm{min}$. Chemical composition of the membranes was studied using Thermo scientific Nicolet iS10 Fourier transform infrared spectroscopy with a resolution standard of $0.4 \mathrm{~cm}^{-1}$. To improve the accuracy of the measurement 32 scans were obtained per sample. The polymer membranes were cut into dumbbell shapes using a cutter of ASTM D-638-V specification and tested on INSTRON Universal Tensile Machine 2519-107. Testing was performed at room temperature using plain rubber grips and a minimum of 5 samples were tested for each membrane.

\section{Results}

The acquired $\mathrm{P}([\mathrm{MATMA}][\mathrm{BF} 4])$ membrane exhibited no elasticity, thus, polymeric support was required. Figure 2 presents the FTIR spectra of pure copolymer membrane and copolymer/PRTIL composites generated using Schemes 1 and 2. The characteristic peak of copolymer at $3263 \mathrm{~cm}^{-1}$ corresponded to the $\mathrm{N}-\mathrm{H}$ group vibrations. Another one is the $\mathrm{C}-\mathrm{H}$ stretch occurs in region of $3095 \mathrm{~cm}^{-1}$ for the copolymer was observed to be disappeared in scheme 1 and scheme 2 which may be attributed to the formation of new N-C-O bonds in the composite materials. Peaks at $2921 \mathrm{~cm}^{-1}$ and $1533 \mathrm{~cm}^{-1}$ resulted due to aliphatic $-\mathrm{C}-\mathrm{H}$ and secondary amide $\mathrm{N}-\mathrm{H}$ bonds respectively [21]. $\mathrm{C}-\mathrm{C}$ bond stretching resulted in the peak at $1433 \mathrm{~cm}^{-1}$ while the 1253 $\mathrm{cm}^{-1}$ peak was attributed to amide $\mathrm{CN}$ stretching [22]. Peak at 1102 $\mathrm{cm}^{-1}$ indicated the presence of $-\mathrm{C}-\mathrm{O}-$ groups. $\mathrm{C}=\mathrm{O}$ stretching at amide group constituted by hydrogen bonded amide resulted in a peak at $1640 \mathrm{~cm}^{-1}$. Peak at $3263 \mathrm{~cm}^{-1}$ of copolymer corresponding to $\mathrm{N}-\mathrm{H}$ bond disappeared in the composite membranes, which may be attributed to the formation of new N-C-O bonds. This became evident by the appearance of a new peak at $3301 \mathrm{~cm}^{-1}$ corresponding to $\mathrm{N}-\mathrm{H}$ stretching for the composite. Formation of a new peak at $1081 \mathrm{~cm}^{-1}$ corresponded for the $\mathrm{C}-\mathrm{C}$ antisymmetric stretching of aliphatic amines.

A small peak at $767 \mathrm{~cm}^{-1}$ corresponding to $\mathrm{BF} 4$ vibrations disappeared due to polymerization and inclusion of BF4 anion in the matrix [23]. IR results pointed out that different chemical transformations occurred in the two synthesis routes, mainly due to the different polymerization mechanisms involved. Along with the polymerization of RTIL, the presence of copolymer (Scheme 2) influenced the polymerization. Images of membranes generated through Schemes 1 and 2 are given in Figure 3. Both the schemes resulted in smooth membranes, though some differences in color were observed.

Table 1 and Figure 4 summarize the mechanical performance of the membranes. The copolymer had significant reduction in the elongation due to the presence of micro-clusters of RTIL into the solid mass (Scheme 1) and photo- polymerization of the RTIL in presence of copolymer (Scheme 2). As a result, tensile modulus increased significantly due to stiffening of the copolymer matrix. 
Citation: George G, Bhoria N, Mittal V (2016) Supported UV Polymerized lonic Liquid Membranes with Block Copolymer. J Membr Sci Technol 6:

Page 3 of 5

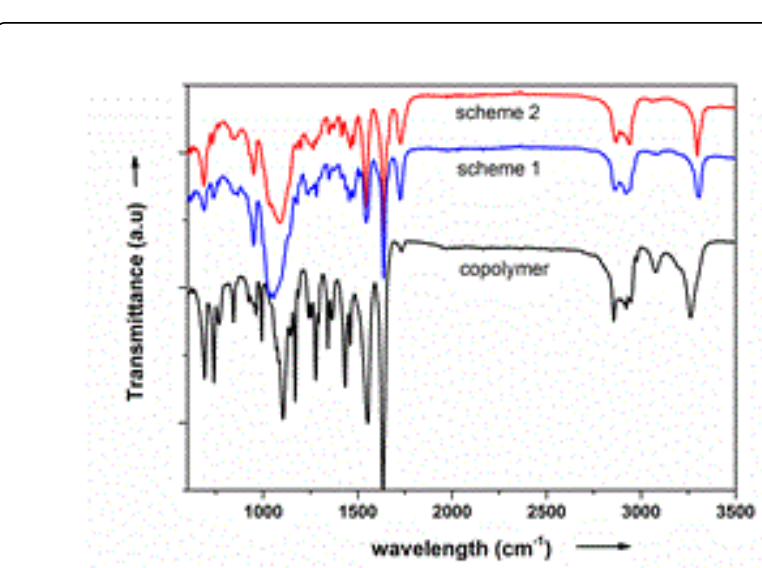

Figure 2: FTIR spectra of pure polymer membrane and its composites from two different schemes.

Larger enhancement of modulus for Scheme 2 polymer can be further attributed to the chemical changes taking place within the membrane during synthesis. Scheme 1 provides a 'local' stiffening action due to the polymerization of RTIL phase, whereas scheme 2 provides a 'membrane-wide' stiffening [24].

As Young's modulus increases, the membranes change from solubility-controlled to diffusion- controlled; this can lead to enhanced selectivity of different sized molecules. The increase of modulus for both schemes proved that both approaches offered enhancement of breaking resistance which is a key factor for the current application of the membranes (separation of acidic content from natural gas flows, commonly under pressure).
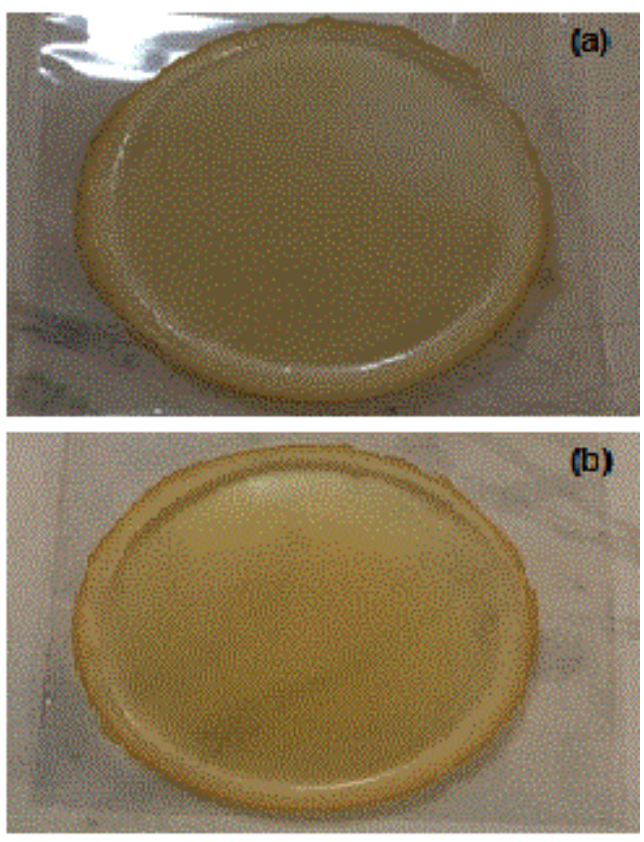

Figure 3: Images of membranes generated through (a) Scheme 1 and (b) Scheme 2.

\begin{tabular}{|l|l|l|l|}
\hline Sample & Modulus (MPa) & Elongation (\%) & UTS (MPa) \\
\hline Copolymer & 137 & 620 & 28 \\
\hline Scheme 1 & 220 & 1.9 & 2.6 \\
\hline Scheme 2 & 335 & 3.3 & 7 \\
\hline
\end{tabular}

Table 1: Mechanical properties of copolymer and supported copolymer membranes.



Figure 4: Stress - strain curve for pure polymer membrane and its composites from two different schemes.

Figure 5 compares the calorimetric properties of copolymer membrane with composite membranes. Table 2 also compares the peak melting point and melt enthalpy for the samples. Scheme 1 resulted in slightly higher peak melting temperatures from $200.5^{\circ} \mathrm{C}$ to $203.2^{\circ} \mathrm{C}$ of polyether and polyamide segments, along with higher enthalpy values probably due to efficient polymerization in absence of copolymer.

It was also observed that RTIL incorporation resulted in decrease of the peak melting point and enthalpy of PA segment, but at a slower rate than reported for non-polymerized RTILs [17]. This DSC provides an excellent tool for confirming the effects of the formation of the composite polymer membrane. The influences on the polymer backbone as a function of thermal stability were also studied.

Table 3 and Figure 6 describe the thermal performance of the membranes. The thermal properties of the composite polymer samples were studied and compared against the pure polymer to determine the influence of structural changes on the polymerisation mechanism.

It was observed that the, the onset temperature shifted towards a lower temperature with the polymerisation. Copolymer exhibited highest onset of degradation temperature. Addition of ionic liquid to the membranes decreased the onset of degradation temperatures; however, the temperatures were still high thus ensuring the thermal stability of the membranes. Membrane generated with Scheme 1 
exhibited superior thermal performance among the composite membranes.

These findings indicated successful synthesis of supported UV cured ionic liquid membranes with controlled structure and properties. Though both the synthesis schemes resulted in structurally strong and thermally stable membranes, the functional performance in terms of gas permeability and selectivity would help to further correlate the membrane structure with the properties.

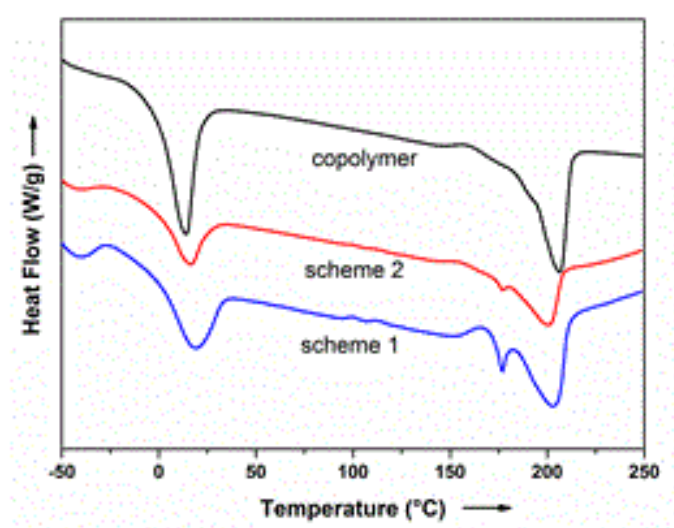

Figure 5: DSC thermograms of pure copolymer membrane and its composites from two different schemes.

\begin{tabular}{|l|l|l|l|l|}
\hline \multirow{2}{*}{ Sample } & \multicolumn{2}{l|}{ Polyether segment } & \multicolumn{2}{l|}{ Polyamide segment } \\
\cline { 2 - 5 } & $\mathbf{T m} 1\left({ }^{\circ} \mathrm{C}\right)$ & $\boldsymbol{\Delta H} \mathbf{1}(\mathbf{J} / \mathbf{g})$ & $\mathbf{T m 2}\left({ }^{\circ} \mathrm{C}\right)$ & $\Delta \mathbf{H 2}(\mathbf{J} / \mathbf{g})$ \\
\hline Copolymer & 14.28 & 27.09 & 208.3 & 28.49 \\
\hline RTIL & - & - & 173.3 & 0.08 \\
\hline P-RTIL & - & - & 145.9 & 0.14 \\
\hline Scheme 1 & 17.6 & 18.5 & 203.2 & 26.7 \\
\hline Scheme 2 & 16.2 & 10.9 & 200.5 & 23.8 \\
\hline
\end{tabular}

Table 2: Peak melting points and melt enthalpy for polyether and polyamide segments.

\begin{tabular}{|l|l|l|l|}
\hline Sample & Onset $\left({ }^{\circ} \mathrm{C}\right)$ & $\begin{array}{l}\mathbf{5 0} \% \text { mass } \\
\text { loss }\left({ }^{\circ} \mathbf{C}\right)\end{array}$ & End degradation $\left({ }^{\circ} \mathbf{C}\right)$ \\
\hline Copolymer & 381 & 406 & 473 \\
\hline RTIL & 307 & 369 & 523 \\
\hline P-RTIL & 330 & 379 & 510 \\
\hline Scheme 1 & 349 & 393 & 500 \\
\hline Scheme 2 & 324 & 380 & 510 \\
\hline
\end{tabular}

Table 3: Thermal performance of the membranes.

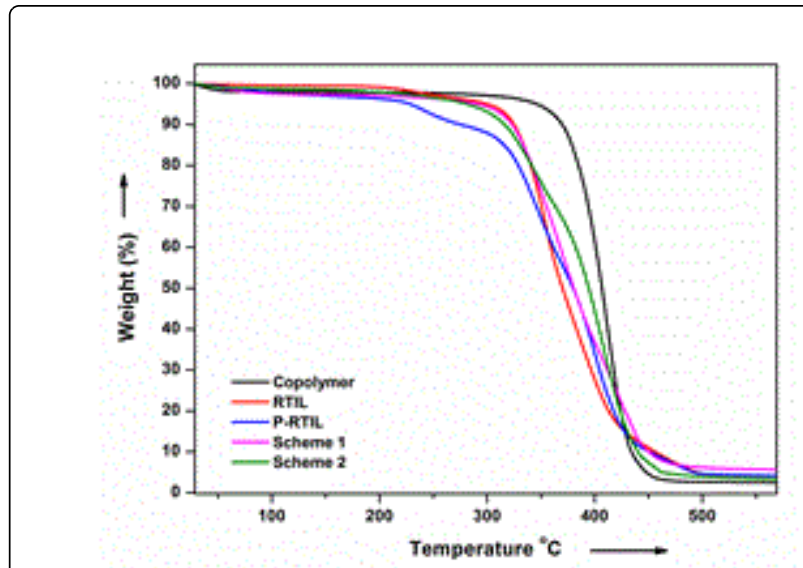

Figure 6: TGA thermograms of pure copolymer membrane and its composites from two schemes.

\section{Conclusion}

This work demonstrated the successful synthesis of the supported UV polymerized ionic liquid membranes with block copolymer using two different synthetic routes. In the first, RTIL was polymerized before the composite preparation and in the second, polymerization occurred in the whole composite's mass. The two different schemes provided different attributes to the membranes. Polymerization of RTIL in presence of copolymer resulted in better mechanical performance, though elongation and tensile strength were decreased as compared to pure copolymer membrane. As compared to the pure copolymer membrane, the polyether segments enhanced the thermal properties such as the melt temperature in the composite membranes. The thermal stability of the composite membranes reduced on the addition of ionic liquid, however, the degradation temperatures were still high, thus, ensuring the thermal stability of the composite membranes. The generated membranes with bound ionic liquid in the structure represent functional membranes for potential use as gas separation membranes, especially for the removal of acid gases like $\mathrm{CO}_{2}$ and $\mathrm{H}_{2} \mathrm{~S}$ from natural gas streams.

\section{Acknowledgment}

The authors thank ADNOC Gas Subcommittee for funding the project "development of two-stage membrane/adsorption acid gas removal process".

\section{References}

1. Baltus RE, Counce RM, Culbertson BH, Duckworth DC (2005) Examination of the potential of ionic liquids for gas separations. Sep Sci Technol 40: 525-541.

2. Bara JE, Gabriel CJ, Hatakeyama ES, Gin DL (2008) Improving CO2 selectivity in polymerized room-temperature ionic liquid gas separation membranes through incorporation of polar substituents. J Mem Sci 321: 3-7.

3. Cadena C, Anthony JL, Shah JK, Morrow TI, Brennecke JF, et al. (2004) Why is $\mathrm{CO} 2$ so soluble in imidazolium-based ionic liquids?. J Am Chem Soc 126: 5300-5308.

4. Scovazzo P, Havard D, McShea M, Morgan D (2009) Long-term, continuous mixed-gas dry fed $\mathrm{CO} 2 / \mathrm{CH} 4$ and $\mathrm{CO} 2 / \mathrm{N} 2$ separation 
Citation: George G, Bhoria N, Mittal V (2016) Supported UV Polymerized lonic Liquid Membranes with Block Copolymer. J Membr Sci Technol 6:

performance and selectivities for room temperature ionic liquid membranes. J Mem Sci 327: 41-48.

5. Jiang YY, Zhou Z, Jiao Z, Li L, Wu YT, et al. (2007) SO2 gas separation using supported ionic liquid membranes. J Phys Chem B 111: 5058-5061.

6. Scovazzo P, Kieft J, Finan DA, Noble R (2004) Gas separations using nonhexafluorophosphate [PF 6]- anion supported ionic liquid membranes. J Mem Sci 238: 57-63.

7. Hu X, Tang JBT, Blasig Ab, Shen YS, Radosz MR (2006) CO2 permeability, diffusivity and solubility in polyethylene glycol-grafted polyionic membranes and their $\mathrm{CO} 2$ selectivity relative to methane and nitrogen. J Mem Sci 281: 130-138.

8. Tang J, Radosz M, Shen Y (2008) Poly (ionic liquid) s as optically transparent microwave-absorbing materials. Macromolecules 41: 493-496.

9. Bara JE, Lessmann S, Gabriel CJ, Noble RD, et al. (2007) Synthesis and performance of polymerizable room-temperature ionic liquids as gas separation membranes. Ind Eng Chem Res 46: 5397-5404.

10. Carlisle TK, Nicodemus GD, Gin DL, Noble RD (2012) CO2/light gas separation performance of cross-linked poly (vinylimidazolium) gel membranes as a function of ionic liquid loading and cross-linker content. J Mem Sci 397: 24-37.

11. Hudiono YC, Carlisle TK, LaFrate AL, Noble RD (2011) Novel mixed matrix membranes based on polymerizable room-temperature ionic liquids and SAPO-34 particles to improve $\mathrm{CO} 2$ separation. J Mem Sci 370: 141-148.

12. Li S, Falconer JL, Noble RD (2004) SAPO-34 membranes for CO2/CH 4 separation. J Mem Sci 241: 121-135.

13. Bara JE, Hatakeyama Es, Gabriel CJ, Zeng X, Lessmann S, et al. (2008) Synthesis and light gas separations in cross-linked gemini room temperature ionic liquid polymer membranes. J of Mem Sci 316: 186-191.

14. Allen NS (1996) Photoinitiators for UV and visible curing of coatings: mechanisms and properties. J Photochem Photobiol A: chem 100: 101-107.
15. Bondar V, Freeman B, Pinnau I (1999) Gas sorption and characterization of poly (ether-b-amide) segmented block copolymers. J Poly Sci 37: 2463-2475.

16. Kim JH, Ha SY, Lee YM (2001) Gas permeation of poly (amide-6-bethylene oxide) copolymer. J Mem Sci 190: 179-193.

17. Bernardo P, Jansen JC, Bazzarelli F, Clarizia G (2012) Gas transport properties of $\mathrm{Pebax}^{\%} / \mathrm{room}$ temperature ionic liquid gel membranes. Sep Pur Technol 97: 73-82.

18. Rabiee H, Ghadimi A, Mohammadi T (2015) Gas transport properties of reverse-selective poly (ether-b-amide6)/[Emim][BF 4] gel membranes for CO 2/light gases separation. J Mem Sci 476: 286-302.

19. Radosz M, Shen Y (2013) Poly (ionic liquid)s as new materials for $\mathrm{CO} 2$ separation and other applications 2013

20. Zhang B, Cai Y, Shang L, Wang H, Cheng Y, et al. (2016) A photonic crystal hydrogel suspension array for the capture of blood cells from whole blood. Nanoscale 8: 3841-3847.

21. Levchik SV, Weil ED, Lewin M (1999) Thermal decomposition of aliphatic nylons. Poly Inter 48: 532-557.

22. Frey BL, Corn RM (1996) Covalent attachment and derivatization of poly (L-lysine) monolayers on gold surfaces as characterized by polarizationmodulation FT-IR spectroscopy. Analy Chem 68: 3187-3193.

23. Henriques RT, Herdtweck E, Kühn FE, Lopes Ad, Mink J, et al. (1998) Synthesis, characterization, and reactions of tetrakis (nitrile) chromium (II) tetrafluoroborate complexes†. J Chem Soc Dalton Trans 8: 1293-1298.

24. Peiffer D, Chung TC, Schulz DN, Agarwal PK, Garner RT, et al. (1986) Rod to coil transition and aggregation in soluble polydiacetylenes: Semidilute regime. J chem phys 85: 4712-4718. 